Paidéia, 2005, 15(30), 119-129

\title{
EVENTOS ESTRESSORES NO DESENVOLVIMENTO DE MENINAS ADOLESCENTES CUMPRINDO MEDIDAS SÓCIO-EDUCATIVAS ${ }^{1}$
}

\author{
Débora Dalbosco Dell'Aglio ${ }^{2}$ \\ UFRGS \\ Sílvia Pereira da Cruz Benetti \\ Luciana Deretti \\ Daniela Bergesch D’Incao \\ Joana Severo Leon \\ UNISINOS, RS.
}

\begin{abstract}
Resumo: Este estudo investigou a ocorrência de eventos estressores no desenvolvimento de 50 adolescentes autoras de ato infracional, com idade entre 13 e 20 anos, que cumpriam medida sócio-educativa em órgão governamental. Os dados foram coletados através de entrevistas semi-estruturadas e de uma versão adaptada do Inventário de Eventos Estressores na Adolescência (IEEA). Foram identificados eventos estressores em diferentes domínios, como a ocorrência de maus-tratos, abuso sexual, uso de drogas, repetência escolar, desemprego e morte dos pais, que se constituem como fatores de risco no seu desenvolvimento. Estes aspectos revelam um ciclo de violência presente na trajetória destas adolescentes, no período anterior ao ato infracional.
\end{abstract}

Palavras- chave: adolescentes; fatores de risco; delinqüência.

\section{STRESSFUL EVENTS ON THE DEVELOPMENT OF DELINQUENT ADOLESCENT GIRLS}

Abstract: This study investigated stressful events present during the development of 50 adolescent girls who had problems with the law, aged 13 to 20 years old and who were in a governmental shelter. Data was collected using a semi-structured interview and an adapted version of the Adolescence Stressful Events Inventory (IEEA). Stressful events in different areas such as child maltreatment, sexual abuse, drugs, school failure, death and unemployed parents were identified, which are risk factors in their development. These aspects reveal the presence of a violence cycle during the adolescent's trajectory, before institutionalization.

Key-words: adolescence; risk factors; delinquency.

A adolescência é um período do ciclo vital, durante o qual é esperado que o indivíduo apresente sentimentos positivos em relação a si mesmo e à sua família, desenvolva habilidades para formar e manter relacionamentos próximos, e seja capaz de atender às demandas do meio no qual está inserido, embora alguns adolescentes, no entanto, possam apresentar problemas psicossociais (Steinberg, 1999). De acordo com Achenbach e Edelbrock (1987), os problemas psicológicos e comportamentais da adolescên-

\footnotetext{
${ }^{1}$ Artigo recebido para publicação em 11/11/2004; aceito em 29/03/ 2005.

${ }^{2}$ Endereço para correspondência: Débora Dalbosco Dell’Aglio, Instituto de Psicologia, UFRGS, Ramiro Barcelos 2600, Porto Alegre, RS, CEP 90035-003, E-mail:_dalbosco@cpovo.net
}

cia podem ser divididos em três grupos: 1) abuso de substâncias; 2) problemas internalizantes ("voltados para dentro", sendo manifestos por meio de perturbações emocionais e cognitivas); e 3) problemas externalizantes ("voltados para fora", manifestos por intermédio de problemas comportamentais ou de atuação). Os problemas externalizantes mais comuns na adolescência são a delinqüência, agressão anti-social e cabular aula (Steinberg, 1999).

A delinqüência tem sido definida tanto como um distúrbio psicossocial como um tipo de psicopatologia. A literatura psicológica refere-se a este fenômeno através de vários termos que são utilizados de modo intercambiável: delinqüência juvenil, distúrbio de conduta, distúrbio de comportamento, comporta- 


\section{Débora Dalbosco Dell’Aglio}

mento anti-social, criminalidade juvenil e problemas de comportamento (Silva, 2002). Neste estudo será utilizado o termo comportamento delinqüente, uma vez que este possui uma conotação de algo mais transitório ou passageiro.

Existem diversos fatores de risco que podem predizer o comportamento delinqüente. Silva e Hutz (2002) afirmam que os fatores de risco para a delinqüência podem ser divididos em fatores de risco individuais (características biológicas, comportamentais e cognitivas do indivíduo) e fatores de risco contextuais (familiares, sociais e experiências de vida negativas ou estressantes). No entanto, raramente um único fator determinará este comportamento, que é, em parte, influenciado pela sobreposição de influências e experiências negativas. Além disso, Dodge e Pettit (2003) destacam que fatores protetivos envolvendo as relações familiares, relações com pares e experiências de vida dentro de instituições, como escola e abrigos, podem mediar a emergência de problemas crônicos de conduta.

Também são citadas como risco outras variáveis contextuais, como práticas parentais inadequadas, envolvimento de familiares com a delinqüência, falta de condições de moradia e experiências traumáticas de abuso, assim como violência física e abuso sexual (Barnow, Lucht \& Freyberger, 2001; Born, Chevalier \& Humblet, 1997). A diminuição do envolvimento parental em famílias numerosas, assim como a modelagem de comportamento mal adaptativo por pares, também pode estar associada a problemas de comportamento na adolescência (Sheley, Mc Gee \& Wright, 1992). Limites rígidos em demasia ou totalmente ausentes, assim como a pouca participação e convívio familiar, são freqüentemente encontrados em famílias de meninas delinqüentes, dificultando seu preparo para enfrentar o mundo e suas adversidades (Assis \& Constantino, 2001; Crosnoe, Erickson \& Dornbusch, 2002; Sá, 2001; Storvoll \& Wichstrom, 2002). O risco para a manifestação do comportamento delinqüente ainda aumenta quando pais ou membros da família usam álcool ou drogas (Herrera \& McCloskey, 2001).

Diferenças na manifestação do comportamento delinqüente e da agressividade entre os sexos têm sido observadas. Segundo Storvoll e Wichstrom (2003), meninos apresentam níveis mais altos de envolvimento em problemas de conduta do que meninas, sendo a idade entre 15 e 16 anos considerada o auge na manifestação deste tipo de comportamento. A prevalência do transtorno de conduta é 6 a 16\% entre os meninos e 2 a $9 \%$ entre as meninas, em uma proporção de 412 meninos para cada menina (Kaplan \& Sadock, 1997). Quanto aos tipos de delitos, meninos cometem mais crimes violentos e contra propriedades, enquanto que meninas estão mais envolvidas em fugas e roubos menores (Herrera \& McCloskey, 2001). Alguns dados nacionais indicam a dimensão do problema da infração feminina entre jovens: em 1997, havia 20.352 adolescentes de 12 a 20 anos cumprindo medida sócio-educativa no país, sendo apenas 7,4\% do sexo feminino (Assis \& Constantino, 2001).

De acordo com Gomide (2000), existe uma socialização diferencial entre os sexos, sendo que muito cedo as meninas aprendem que a agressão física é um comportamento indesejável e, então, adquirem comportamentos mais compatíveis e esperados para o seu sexo. Há, também, diferenças quanto ao sexo na associação com a violência: adolescentes do sexo masculino são mais vítimas da violência extrafamiliar; apresentam mais freqüentemente comportamentos agressivos, como lutas e brigas, envolvem-se mais em roubo e uso de armas, vandalismo e oposição escolar do que as meninas (Gomide, 2000; Storvoll \& Wichstrom, 2002). Estas sofrem, mais freqüentemente, violência doméstica, abuso sexual e negligência (Kristensen, Oliveira \& Flores, 2000; Salzinger, Feldman, Stockhammer \& Hood, 2002). Ainda é observada uma maior prevalência de desordens internalizantes, como a depressão, entre as meninas, e desordens externalizantes, como expressão de sentimentos através de comportamentos agressivos e abuso de drogas ou álcool, entre os meninos (Steinberg, 1999).

Especificamente quanto a adolescentes autoras de ato infracional, Assis e Constantino (2001) afirmam que a infração juvenil feminina é facilitada por necessidades financeiras, pela desigualdade social e consumismo exagerado, assim como por gastos com drogas, problemas familiares, maus tratos, especialmente em comunidades violentas. Além disso, as autoras apontam estudos americanos que indicam relações entre abuso e delinqüência, demonstrando que metade das meninas envolvidas no universo infracional 
provém de grupos minoritários, $61 \%$ já sofreram abuso físico (geralmente recorrente), 54,3\% foram vítimas de abuso sexual (comumente repetido), 80,7\% já fugiram de casa e 53,8\% já tentaram suicídio, sendo que o motivo mais alegado foi o de que ninguém se importava com suas vidas (Assis \& Constantino, 2001). Uma alta relação entre o abuso físico na infância e a subseqüente conduta delinqüente também foi observada na amostra feminina do estudo de Herrera e McCloskey (2001).

Considerando que o comportamento delinqüente em meninas vem ocorrendo com índices cada vez mais elevados (Chesney-Lind \& Paramore, 2001; McKnight \& Loper, 2002; Storvoll \& Wichstrom, 2003) e que há necessidade de pesquisas que possibilitem uma melhor compreensão desta problemática entre adolescentes do sexo feminino, este estudo teve como objetivo investigar a ocorrência e o impacto de eventos estressores no desenvolvimento de adolescentes que cumprem medidas sócioeducativas.

\section{Método}

\section{Participantes}

Participaram deste estudo 50 adolescentes autoras de ato infracional, com idade variando entre 13 a 20 anos ( $M=16,39 ; \mathrm{DP}=1,82)$, com tempo médio de institucionalização de 3,5 meses ( $\mathrm{DP}=5,3)$, sendo que $72 \%$ eram oriundas do interior do Estado do Rio Grande do Sul e 28\% da capital (Porto Alegre), e estavam cumprindo medidas de privação de liberdade (30\%), restritiva de liberdade (20\%), regressão de medida (14\%) ou internação provisória (32\%). Os motivos pelos quais estas adolescentes encontravamse cumprindo medidas sócio-educativas se referiam a ato infracional contra pessoa (66\%), ato infracional relacionado a tóxicos (10\%), regressão de medida (14\%) ou ato infracional contra o patrimônio (6\%). A escolaridade das participantes variou desde "nunca estudou” até o primeiro ano do Ensino Médio: duas participantes nunca estudaram (4\%), 24 estão entre a primeira e quinta série do Ensino Fundamental (48\%), 18 estão entre a sexta e oitava série (36\%) e seis participantes estão no primeiro ano ou supletivo do segundo grau (12\%).

\section{Instrumentos e Procedimentos}

Para avaliar os eventos de vida estressores, foi utilizada uma entrevista semi-estruturada, com o objetivo de levantar dados sociodemográficos, e uma versão adaptada do Inventário de Eventos Estressores na Adolescência (IEEA; Ferlin, Lima, Alchieri, Kristensen \& Flores, 2000). O instrumento adaptado foi composto por 64 itens na forma de eventos de vida estressores. Para cada item, o participante deveria indicar em uma alternativa sim/não se o evento ocorreu e, a partir disso, em uma escala Likert de cinco pontos, informar o impacto atribuído a cada evento de fato experienciado. Essa versão adaptada apresentou elevada consistência interna (alpha de Cronbach $=0,92$ ), mostrando-se confiável na avaliação de eventos de vida estressores em adolescentes (Kristensen, Dell’Aglio, Leon \& D’Incao, 2004).

As entrevistas foram realizadas individualmente, assim como a aplicação do IEEA, em sala disponibilizada pela instituição, sendo o instrumento preenchido pelas próprias pesquisadoras, em uma mesma sessão de coleta. O projeto de pesquisa foi aprovado pelo Comitê de Ética da UFRGS e foram tomados os cuidados éticos referentes a este tipo de estudo. Foi obtida a concordância da Instituição, que mantém formalmente a guarda das adolescentes, e foi solicitado às participantes o consentimento livre e esclarecido quanto à sua participação no estudo, assegurando-lhes sigilo e confidencialidade.

Para possibilitar uma análise que privilegiasse os contextos de desenvolvimento das adolescentes, os eventos estressores, levantados através do IEEA (versão adaptada), foram categorizados, neste estudo, em diferentes domínios. A concordância entre juízes, na classificação dos eventos estressores em domínios, foi de 93,75\%. Os domínios são os seguintes:

1. Domínio Familiar: caracterizado por eventos que envolvem conflitos diretamente ligados ao ambiente familiar, com a própria adolescente e demais membros da família.

2. Domínio Escolar: inclui eventos ocorridos no ambiente escolar, envolvendo a própria adolescente, colegas ou professores.

3. Domínio Social: inclui os conflitos na relação da adolescente com outras pessoas, desde que as mesmas não sejam vinculadas exclu- 
122 Débora Dalbosco Dell'Aglio

sivamente à família, escola ou instituição responsável pela mesma.

4. Domínio Judicial/institucional: refere-se a eventos que envolvem esferas legais e órgãos que visam à proteção ao adolescente, como por exemplo, o conselho tutelar e instituições de abrigo.

5. Domínio Sexual: caracterizado por estressores relacionados à sexualidade da adolescente.

6. Domínio Pessoal: inclui situações pessoais que não estavam contempladas nas categorias anteriores.

\section{Resultados}

Os dados sociodemográficos das participantes do estudo revelaram que 68\% destas adolescentes já desenvolveram alguma atividade remunerada (trabalho formal e informal) e que, atualmente, $62 \%$ delas participam de oficinas na própria instituição. Quanto à moradia anterior, 68\% das adolescentes moravam com a família biológica, 14\% com o companheiro, $8 \%$ vinham de outra instituição, $6 \%$ moravam nas ruas ou outro tipo de moradia e $4 \%$ delas moravam com família adotiva. A maioria destas adolescentes continuava mantendo contato com suas famílias (86\%), sendo que, no entanto, apenas $16 \%$ delas permaneceram junto à sua família de origem durante toda a infância e adolescência, pois, em geral, suas histórias apresentam seqüências de abandonos, separações e vivências de rua. Em relação à gravidez na adolescência, $48 \%$ já havia ficado grávida pelo menos uma vez, sendo que deste percentual, 17 adolescentes tinham de um a três filhos e oito delas haviam tido aborto espontâneo ou provocado.

Foram observadas as freqüências e impacto dos eventos estressores levantados, apresentados nas Tabelas 1 e 2.

No domínio familiar, os eventos mais freqüentes foram: "morte de outro familiar", "ter que obedecer às ordens de seus pais", "ter brigas com irmãos", "um dos pais ter filhos com outros parceiros" e "um dos pais ficar desempregado". Os eventos referidos como causadores de alto impacto foram: "não receber cuidado e atenção dos pais", "ser impedida de ver os pais", "morte de irmãos", "ter familiares com ferimentos ou doenças" e "morte de um dos pais".
No domínio escolar, os eventos mais freqüentes foram: "ter provas no colégio", "mudar de colégio", "rodar de ano na escola" e "ser expulsa da sala de aula pela professora"; enquanto os de maior impacto foram "ter mau relacionamento com colegas" e "ter dificuldades de adaptação/ajustamento na escola".

No domínio judicial/institucional, os eventos mais freqüentes foram: "ser levada para a Febem", "ter problemas com a justiça”, "ter problemas com a polícia” e "ser levada para o conselho tutelar"; e os de maior impacto foram: "ser levada para a Febem”, "ter problemas com a polícia” e "ter problemas com a justiça”.

No domínio social foram mais freqüentes os eventos: "ser xingada ou ameaçada verbalmente", "terminar namoro", "discutir com amigos", "mudar de casa ou de cidade” e "envolver em brigas com agressão física”; e os de maior impacto foram: "morte de amigo", "ter problemas com autoridades ou chefia”, "sentir-se rejeitada por colegas e amigos”, “envolver-se em brigas com agressão física” e "sofrer humilhação ou ser desvalorizada”.

No domínio sexual, os eventos que apresentaram maior freqüência foram: "ficar grávida", "ser tocada sexualmente contra a vontade" e "fazer aborto"; enquanto os de maior impacto foram: "ser estuprada", "ser tocada sexualmente contra a vontade" e "fazer aborto". Embora no IEEA tenha sido apontada a ocorrência de estupro em apenas 6\% das participantes, foi realizado um levantamento da ocorrência de outras formas de abuso sexual, a partir dos dados levantados na entrevista, incluindo os casos em que estão presentes a exploração sexual, gravidez antes dos 14 anos, ser tocada sexualmente contra a vontade e o estupro, chegando-se a um índice de 34\% de abuso sexual.

Por fim, o domínio pessoal apresentou como eventos mais freqüentes: "ter crise nervosa", "não ter dinheiro" e "usar drogas"; e de maior impacto: "ter sofrido algum tipo de violência”, "ser assaltada" e "ter crise nervosa".

\section{Discussão}

Neste estudo foram investigados os eventos estressores vivenciados por adolescentes do sexo feminino, que cumpriam medidas sócio-educativas, procurando-se compreender suas trajetórias de vida 
Tabela 1 - Percentuais de ocorrência e impacto dos eventos estressores nos domínios familiar, escolar e judicial/institucional

\begin{tabular}{|c|c|c|c|c|c|}
\hline \multirow[b]{2}{*}{ Domínio } & \multirow[b]{2}{*}{ Evento Estressor } & \multirow{2}{*}{$\begin{array}{l}\text { Ocorrência } \\
\text { (\%) }\end{array}$} & \multicolumn{3}{|c|}{ Impacto (\%) } \\
\hline & & & Baixo & Médio & Alto \\
\hline & Morte de outro familiar & 86 & 25,6 & 2,3 & 72,1 \\
\hline & Ter que obedecer às ordens dos pais & 80 & 37,5 & 17,5 & 45,0 \\
\hline & Ter brigas com irmãos (as) & 76 & 26,3 & 21,1 & 52,6 \\
\hline & Um dos pais ter filhos com outros parceiros & 72 & 63,9 & 13,9 & 22,2 \\
\hline & Um dos pais ficar desempregado & 68 & 14,7 & 11,8 & 73,5 \\
\hline \multirow{12}{*}{ Familiar } & Ter familiares com ferimentos ou doenças & 64 & 15,6 & 6,3 & 78,1 \\
\hline & Separação dos pais & 62 & 29,0 & 6,5 & 64,5 \\
\hline & Não receber cuidado e atenção dos pais & 62 & 6,5 & 6,5 & 87,1 \\
\hline & Um dos pais se casar novamente & 60 & 50,0 & 3,3 & 46,7 \\
\hline & Ser impedida de ver os pais & 60 & 6,7 & 10,0 & 83,3 \\
\hline & Sofrer agressão física ou ameaça por parte dos pais & 52 & 19,2 & 7,7 & 73,1 \\
\hline & Ser rejeitada pelos familiares & 50 & 4,2 & 20,8 & 75,0 \\
\hline & Assumir o sustento da família & 32 & 37,5 & 25 & 37,5 \\
\hline & Morte de irmão(s) & 30 & 20,0 & - & 80,0 \\
\hline & Morte de um dos pais & 22 & 11,6 & 11,6 & 76,7 \\
\hline & Um dos pais ter que morar longe por causa do serviço & 22 & 36,4 & 9,1 & 54,5 \\
\hline & Ter sido adotada & 6 & 33,3 & - & 66,7 \\
\hline \multirow{9}{*}{ Escolar } & Ter provas no colégio & 76 & 55,3 & 15,8 & 28,9 \\
\hline & Mudar de colégio & 76 & 36,8 & 28,9 & 34,2 \\
\hline & Rodar de ano na escola & 68 & 35,3 & 23,5 & 41,2 \\
\hline & Ser expulsa da sala de aula pela professora & 56 & 35,7 & 17,9 & 46,4 \\
\hline & Ter problemas com professores & 52 & 30,8 & 23,1 & 46,2 \\
\hline & Ser suspensa da escola & 50 & 44,0 & 16,0 & 40,0 \\
\hline & Ter mau relacionamento com colegas & 44 & 13,6 & 9,1 & 77,3 \\
\hline & Ter dificuldades de adaptação/ajustamento na escola & 44 & 4,5 & 27,3 & 68,2 \\
\hline & Ser expulsa da escola & 28 & 28,6 & 14,3 & 57,1 \\
\hline \multirow{5}{*}{$\begin{array}{l}\text { Judicial/ } \\
\text { Institucional }\end{array}$} & Ser levada para Febem & 100 & 8,0 & 4,0 & 88,0 \\
\hline & Problemas com a justiça & 94 & 10,6 & 19,1 & 70,2 \\
\hline & Problemas com a polícia & 92 & 17,4 & 6,5 & 76,1 \\
\hline & Ir para o conselho tutelar & 80 & 37,5 & 22,5 & 40,0 \\
\hline & Ser levada para uma instituição de abrigo & 56 & 42,9 & 17,9 & 39,3 \\
\hline
\end{tabular}


Tabela 2 - Percentuais de ocorrência e impacto dos eventos estressores nos domínios social, sexual e pessoal

\begin{tabular}{|c|c|c|c|c|c|}
\hline \multirow[b]{2}{*}{ Domínio } & \multirow[b]{2}{*}{ Evento Estressor } & \multirow{2}{*}{$\begin{array}{l}\text { Ocorrência } \\
\text { (\%) }\end{array}$} & \multicolumn{3}{|c|}{ Impacto (\%) } \\
\hline & & & Baixo & Médio & Alto \\
\hline \multirow{15}{*}{ Social } & Ser xingada ou ameaçada verbalmente & 94 & 27,7 & 12,8 & 59,6 \\
\hline & Terminar namoro & 92 & 26,1 & 13,0 & 60,9 \\
\hline & Discutir com amigos & 92 & 8,7 & 15,2 & 76,1 \\
\hline & Mudar de casa ou cidade & 82 & 34,1 & 22,0 & 43,9 \\
\hline & Envolver-se em brigas com agressão física & 80 & 15,0 & 5,0 & 80,0 \\
\hline & Sofrer humilhação ou ser desvalorizada & 78 & 5,1 & 15,4 & 79,5 \\
\hline & Ser impedida de ir a festas ou passeios & 78 & 10,3 & 15,4 & 74,4 \\
\hline & Sofrer castigos e punições & 74 & 13,5 & 8,1 & 78,4 \\
\hline & Morte de amigo & 70 & 5,7 & 2,9 & 91,4 \\
\hline & Ter amigos com ferimentos ou doenças & 66 & 6,1 & 18,2 & 75,8 \\
\hline & Ter problemas com autoridades ou chefia & 50 & 8,0 & 8,0 & 84,0 \\
\hline & Sentir-se rejeitada por colegas e amigos & 48 & 8,0 & 12,0 & 80,0 \\
\hline & Não ter amigos & 46 & 13,0 & 13,0 & 73,9 \\
\hline & Ter problemas com outros pela sua raça & 36 & 22,2 & 5,6 & 72,2 \\
\hline & Ter dificuldades em fazer amizades & 36 & 33,3 & 16,7 & 50 \\
\hline \multirow{4}{*}{ Sexual } & Ficar grávida & 48 & 70,8 & 12,5 & 16,7 \\
\hline & Ser tocada sexualmente contra a vontade & 34 & 5,9 & 5,9 & 88,2 \\
\hline & Fazer aborto & 16 & - & 25,0 & 75,0 \\
\hline & Ser estuprada & 6 & - & 8,3 & 91,7 \\
\hline \multirow{14}{*}{ Pessoal } & Ter crise nervosa & 90 & 4,4 & 8,9 & 86,7 \\
\hline & Não ter dinheiro & 86 & 25,6 & 25,6 & 48,8 \\
\hline & Usar drogas & 70 & 28,6 & 11,4 & 60,0 \\
\hline & Ter dúvidas quanto à aparência e mudanças no corpo & 66 & 36,4 & 15,2 & 48,5 \\
\hline & Não conseguir emprego & 64 & 9,4 & 9,4 & 81,3 \\
\hline & Ser pobre & 60 & 53,3 & 6,7 & 40 \\
\hline & Ficar pobre & 54 & 18,5 & 7,4 & 74,1 \\
\hline & Ter sofrido algum tipo de violência & 54 & - & 11,1 & 88,9 \\
\hline & Sofrer acidente & 48 & 16,7 & 12,5 & 70,8 \\
\hline & Ter dormido na rua & 44 & 13,6 & 27,3 & 59,1 \\
\hline & Ter doenças graves ou lesões & 44 & 9,1 & 18,2 & 72,7 \\
\hline & Perder emprego & 40 & 15 & 10 & 75 \\
\hline & Ser assaltada & 32 & - & 12,5 & 87,5 \\
\hline & Ter problemas no trabalho & 28 & 14,3 & 14,3 & 71,4 \\
\hline
\end{tabular}

e a manifestação do comportamento delinqüente na adolescência. Os eventos citados como mais impactantes, tanto no domínio familiar, acadêmico ou social, referiram-se principalmente a questões que envolviam relações interpessoais, nas quais freqüentemente esteve presente a violência. Mais da metade das participantes do presente estudo reportou sofrer agressão física ou ameaça de agressão por parte dos pais, tendo sido atribuído um alto impacto frente a estas situações. Estes dados apóiam a literatura (Assis \& Constantino, 2001; Barnow, Lucht \& Freyberger,
2001; Herrera \& McCloskey, 2001), que tem apontado a violência familiar e especialmente o abuso infantil, como principais preditores para o comportamento delinqüente.

No estudo de Altoé (1993), com presidiários brasileiros, os dados apontaram a presença de rompimento ou enfraquecimento dos vínculos familiares durante a infância e adolescência. Neste estudo, foi evidenciado que poucas adolescentes tiveram um convívio familiar estável ao longo de suas vidas, tendo predominado o abandono, a rejeição e ainda a substituição ou 
ausência de uma ou ambas as figuras cuidadoras, além da institucionalização durante a infância. Destaca-se ainda que os eventos familiares de maior impacto foram "não receber cuidado e atenção dos pais" e "ser impedida de ver os pais", demonstrando a importância da presença da família durante a adolescência. Para Steinberg (1999), o afeto e a proximidade familiar possibilitam melhores condições para o adolescente enfrentar experiências estressantes, sendo que o apoio familiar se constitui no mais importante fator de proteção na adolescência.

Questões referentes a novas configurações familiares também se mostraram presentes no desenvolvimento das participantes deste estudo, como por exemplo, a separação dos pais, a união destes com novos parceiros, assim como a existência de irmãos oriundos destes relacionamentos. Para McKnight e Loper (2002), as adolescentes que moram com apenas uma das figuras parentais estão mais propensas a se envolver em atos violentos do que as que vivem com ambos os pais, situação esta que está diretamente relacionada, na maioria das vezes, à separação dos mesmos. Saner e Ellickson (1996) assinalam que o desmembramento familiar, devido à separação dos pais ou a morte de um deles, aumenta consideravelmente a probabilidade de envolvimento em diversas formas de violência, sendo importante destacar que, neste estudo, $22 \%$ das adolescentes apontaram a perda de pelo menos um dos pais, e, para $76,7 \%$ destas, este evento foi apontado como de alto impacto.

Também foi constatada defasagem escolar entre as participantes, que apresentaram uma baixa média de escolaridade e $68 \%$ de reprovação. A defasagem escolar também é apontada como um fator de risco para o comportamento delinqüente. Para Saner e Ellickson (1996), o baixo desempenho acadêmico tem sido relacionado a diversos tipos de comportamento violento. McKnight e Loper (2002) apontam uma relação entre menor probabilidade de envolvimento em atos infracionais e alta motivação acadêmica, percepção positiva de si mesmo e da relação com os pais. Lotz e Lee (1999) encontraram uma forte relação entre experiências escolares negativas e o envolvimento em atividades delinqüentes, sendo que os adolescentes investigados preferem despender seu tempo livre envolvidos em atividades arriscadas e ilegais a se dedicarem aos estudos ou até mesmo passar em companhia da família. Crosnoe, Erickson e Dornbusch (2002), em um estudo realizado com adolescentes de ambos os sexos, encontraram uma relação direta entre realização e boa orientação escolar e baixos níveis de delinquiência, sendo que se sentir emocionalmente ligado aos professores e ter um bom aproveitamento na escola funcionaram como fatores protetivos contra a influência de pares delinqüentes e conseqüente envolvimento com este tipo de comportamento. Hoffmann e Xu (2002) também observaram que, quando as percepções acerca da escola geram sentimentos de segurança e satisfação, há um efeito no comportamento delinqüente, diminuindo sua manifestação.

Nos diversos domínios investigados, encontrouse uma alta freqüência e impacto nos eventos que envolviam a relação com pares, apontando a importância destes no desenvolvimento destas adolescentes. Fergusson e Horwood (1999) demonstraram que fatores de risco para a delinqüência estão largamente associados ao convívio com pares, sendo que estes riscos aumentam quando os adolescentes estão expostos à desvantagem social e econômica, família disfuncional, pais que cometeram crime ou se drogam, uso de substâncias e problemas de conduta durante seu desenvolvimento. Lotz e Lee (1999) também apontam uma expressiva relação entre a companhia de pares e o envolvimento em atividades delinqüentes. Para estes autores, a semelhança de interesses e experiências acaba por aumentar as influências dentro do grupo de pares, fazendo com que os adolescentes inspirem e incitem uns aos outros na experimentação de comportamentos novos e muitas vezes excitantes. Por outro lado, Regnerus (2002) afirma que pares delinqüentes não são necessariamente responsáveis pela propensão do adolescente a este comportamento, sendo que a intensidade das amizades tem mais influência do que o número de amigos delinqüentes. Quanto a diferenças de sexo, amigos delinqüentes aparecem como fatores de risco para o comportamento anti-social, sendo que entre os meninos o risco desta interação é significativamente maior do que entre as meninas (Crosnoe, Erickson \& Dornbusch, 2002).

As participantes consideraram os eventos relacionados ao sistema judiciário como altamente 


\section{Débora Dalbosco Dell’Aglio}

impactantes em suas vidas, o que pode estar sendo influenciado até mesmo pela imagem social criada em torno desta condição. Segundo Nurse (2002), a situação de institucionalização para cumprimento de medidas judiciais vem acompanhada, muitas vezes, de uma imagem estigmatizada a respeito do funcionamento destas instituições. Em estudo realizado no Brasil, por Altoé (1993), foi observada uma alta freqüência de institucionalização na adolescência entre presidiários, sugerindo que as internações dos jovens que apresentam “comportamento anti-social”, com a exclusão do convívio social, funcionam apenas como uma medida disciplinar e punitiva, que não se mostra eficiente na promoção de um redirecionamento na trajetória de vida destes indivíduos. Além disso, esta autora ressalta que, nas escolas, as professoras têm, muitas vezes, uma visão estigmatizada em relação às crianças e adolescentes institucionalizados, vendo-os como "menores", pobres, perigosos, desinteressados, pouco inteligentes e que não fazem bom proveito das oportunidades oferecidas pela instituição (Altoé, 1990). Assim, pode-se entender que o fato destas adolescentes passarem por um período de institucionalização para cumprimento de medidas sócio-educativas, torna-se por si só mais um fator de risco para o seu desenvolvimento.

Diversos estudos têm apontado uma maior freqüência de violência doméstica, abuso sexual e negligência contra meninas (Kristensen, Oliveira \& Flores, 2000; Steinberg, 1999). Miller, Trapani, FejesMendoza e Eggleston (1995) demonstraram que, entre jovens delinqüentes, há uma maior incidência de abuso sexual de meninas, sendo que em seu estudo $81 \%$ das meninas e $13 \%$ dos meninos haviam sofrido abuso sexual. Mulheres vítimas de abuso sexual estão significativamente mais propensas a serem presas pelo envolvimento em crimes violentos ao longo de suas vidas do que mulheres que nunca sofreram algum tipo de abuso (Siegel \& Williams, 2003). Neste estudo, foi observado um índice mais elevado de abuso sexual (34\%) do que em outro estudo, também realizado em Porto Alegre, com adolescentes estudantes da rede estadual, quando foi encontrada uma freqüência de 2,3\% de abuso sexual (Polanczyk, Zavaschi, Benetti, Zenker \& Gammerman, 2003). Este dado, que aponta um índice maior de abuso sexual entre as participantes, corrobora a afirmação de
McKnight e Loper (2002), que apontam o abuso sexual como fator de risco para o comportamento delinqüente. Para Silva e Hutz (2002), o abuso é considerado como uma experiência de vida negativa ou estressante, que acarreta um alto grau de tensão, interferindo nos padrões esperados de resposta, o que pode pressupor uma alta probabilidade de desenvolvimento de algum tipo de desordem. Segundo Assis e Constantino (2001), jovens delinqüentes trazem, muitas vezes, relatos de abuso sexual, sendo que quando o agressor é uma pessoa da família, o problema criado é muito grave, já que atinge o seu núcleo fundamental de proteção, confiança, afeto e relação de dependência.

Também foi observada, entre as adolescentes participantes, uma alta incidência de gravidez, abuso sexual e aborto. Estudos têm indicado que, geralmente, as adolescentes grávidas estão inseridas em famílias com problemas de comunicação, uso de álcool e pai ausente, além de apresentarem baixas perspectivas acadêmicas e não gostarem de ir à escola (Adams \& East, 1999; Guijarro, Naranjo, Padilha, Gutierez, Lammers \& Blum, 1999). Além disso, relatos de adolescentes grávidas indicam uma maior incidência de abuso físico no passado do que adolescentes não grávidas, sendo que as primeiras iniciam suas relações sexuais mais cedo e com parceiros mais velhos (Adams \& East, 1999).

O uso de drogas, que apresentou uma alta freqüência neste estudo, também tem sido relacionado na literatura ao comportamento infrator na adolescência. Estudos trazem evidências do abuso de substância em amostras de menores institucionalizadas, sendo esta uma forma de comportamento de risco que tem um importante papel no desenvolvimento da delinqüência juvenil feminina (Lenssen, Deoreleijers, Van Dijk \& Hartman, 2000; McKnight \& Loper, 2002). A combinação do uso de drogas ilícitas com outros fatores de risco torna ainda maior a propensão à violência nesta população. O contato de adolescentes com familiares e amigos usuários de drogas torna-as ainda mais propensas a consumir e até mesmo traficar drogas, assim como à exibição de comportamentos com altos níveis de violência (Saner \& Ellickson, 1996).

A situação sócio-econômica em que estas adolescentes estão inseridas, que fica evidente através dos itens "ser pobre”, "não ter dinheiro" e "pais 
desempregados”, também deve ser considerada como um fator de risco para seu desenvolvimento. A literatura faz referência à pobreza como um aspecto importante no crescimento da delinqüência juvenil (Assis \& Constantino, 2001; McKnight \& Loper, 2002; Saner \& Ellickson, 1996), relacionando o envolvimento de jovens em comportamentos violentos a um baixo nível sócio-econômico e educacional familiar. Para Herrera e McCloskey (2001), a situação de miséria tem sido relacionada à violência intrafamiliar, em especial à violência conjugal, assim como a altos níveis de psicopatologia, como o abuso de álcool e drogas e a criminalidade entre os pais, contribuindo para o surgimento de comportamento violento nos jovens que se desenvolvem neste contexto. Saner e Ellickson (1996) encontraram uma correlação positiva entre o desemprego dos pais e diversos tipos de comportamento violento na adolescência.

\section{Considerações Finais}

Muitos dos eventos identificados neste estudo estão relacionados à própria etapa da adolescência, enquanto outros refletem características dos diferentes domínios em que as adolescentes estão inseridas, indicando uma fragilidade nas relações familiares, dificuldades de relacionamento e, ainda, a presença de ambientes violentos. A ocorrência de gravidez na adolescência, uso de drogas, problemas financeiros, abuso sexual e físico, assim como falta de apoio familiar e falta de perspectiva acadêmica são fatores de risco presentes no desenvolvimento destas adolescentes, tornando-as vulneráveis e acarretando impacto no seu bem-estar psicológico. Dessa forma, pode-se observar uma sobreposição de influências e experiências negativas, com uma alta ocorrência de eventos estressores em suas vidas, e ao mesmo tempo uma falta de fatores protetivos em seus contextos de inserção, que pudessem funcionar como mediadores neste processo. Assim, os dados levantados neste estudo apontam a presença de uma trajetória de desenvolvimento marcada por fatores de risco, que certamente contribuíram para a manifestação do comportamento infrator, embora se compreenda também que este comportamento pode se constituir numa forma de enfrentamento das dificuldades que vêm sendo vivenciadas em suas vidas.
Desta forma, é importante que se leve em consideração as características dos contextos de desenvolvimento destas adolescentes, já que a escola, o abrigo para cumprimento de medidas sócio-educativas e a própria família são instituições que deveriam auxiliá-las e protegê-las, funcionando como redes de apoio. Torna-se necessário, então, o desenvolvimento de programas de prevenção que possibilitem a identificação dos fatores de risco, presentes nos diferentes contextos, assim como trabalhos de capacitação dos profissionais que atuam junto a esta população. Através do fortalecimento das redes de apoio disponíveis a estas adolescentes, as instituições com as quais têm contato poderão atuar como mediadores para um desenvolvimento mais adaptativo.

\section{Referências Bibliográficas}

Achenbach, T. \& Edelbrock, C. (1987). The manual for the youth self-report and profile. Burington: University of Vermont.

Adams, J. A. \& East, P. L. (1999). Past physical abuse is significantly correlated with pregnancy as an adolescent. Journal of Pediatric Adolescent Gynecology, 12, 133-138.

Altoé, S. E. (1990). Infâncias perdidas. Rio de Janeiro: Editora Xenon.

Altoé, S. E. (1993). De "menor" a presidiário: Trajetória inevitável? Rio de Janeiro: Editora Universitária Santa Úrsula.

Assis, S. G. \& Constantino, P. (2001). Filhas do mundo: Infração juvenil feminina no Rio de Janeiro. Rio de Janeiro: Editora Fiocruz.

Barnow, S., Lucht, M. \& Freyberger, H. J. (2001). Influence of punishment, emotional rejection, child abuse, and broken home on aggression in adolescence: An examination of aggressive adolescents in Germany. International Journal of Descriptive and Experimental Psychopathology, Phenomenology and Clinical Diagnostic, 34(4), 167-173.

Born, M., Chevalier, V. \& Humblet, I. (1997). Resilience, desistence and delinquent career of adolescent offenders. Journal of Adolescence, 20(6), 679-694. 


\section{Débora Dalbosco Dell'Aglio}

Chesney-Lind, M. \& Paramore, V. V. (2001). Are girls getting more violent? Journal of Contemporary Criminal Justice, 17(2), 142-166.

Crosnoe, R., Erickson, K. G. \& Dornbusch, S. M. (2002). Protective functions of family relationships and school factors on the deviant behavior of adolescent boys and girls. Youth \& Society, 33(4), 515-544.

Dodge, K. A. \& Pettit, G. S. (2003). A biopsychosocial model of the development chronical conduct problems in adolescents. Developmental Psychology, 39(2), 349-371.

Fergusson, D. M. \& Horwood, J. L. (1999). Prospective childhood predictors of deviant peer affiliations in adolescence. Journal of Child Psychology and Psychiatry and Allied Disciplines, 40(4), 581-592.

Ferlin, M., Lima, J. S., Alchieri, J. C., Kristensen, C. H. \& Flores, R. Z. (2000). Desenvolvimento do inventário de eventos estressores na adolescência (IEEA). Resumos das Comunicações. Semana de Pesquisa e Iniciação Científica (pp. 204-205). São Leopoldo: Unisinos.

Gomide, P. I. C. (2000). A influência de filmes violentos em comportamento agressivo de crianças e adolescentes. Psicologia Reflexão e Crítica, 13(1), 127-141.

Guijarro, S., Naranjo, J., Padilha, M., Gutierez, R., Lammers, C. \& Blum, R. (1999). Family risk factors associated with adolescent pregnancy: Study of a group of adolescent girls and their families in Ecuador. Journal of Adolescent Health, 25(2), 166-172.

Herrera, V. M. \& McCloskey, L. A. (2001). Gender differences in the risk for delinquency among youth exposed to family violence. Child Abuse \& Neglect, 23(11), 1037-1051.

Hoffmann, J. P. \& Xu, J. (2002). School activities, community service, and delinquency. Crime \& Delinquency, 48(2), 568-591.

Kaplan, H. I. \& Sadock, B. J. (1997). Compêndio de psiquiatria. Porto Alegre: Artes Médicas.
Kristensen, C. H, Dell’Aglio, D. D, Leon, J. S. \& D’Incao, D. B. (2004). Análise da freqüência e do impacto de eventos estressores em uma amostra de adolescentes. Interação em Psicologia, 8 (1), 45-55.

Kristensen, C. H., Oliveira, M. S. \& Flores, R. Z. (2000). Violência contra crianças e adolescentes na Grande Porto Alegre. Parte B: Pode piorar? Em AMENCAR (Org.), Violência doméstica (pp. 104-117). Brasília: UNICEF.

Lenssen, S. A. M. V., Deoreleijers, T. A. H., Van Dijk, M. E. \& Hartman, C. A. (2000). Girls in detention: What are their characteristics? A project to explore and document the character of this target group and the significant ways in which it differs from one consisting of boys. Journal of Adolescence, 23(2), 287-303.

Lotz, R. \& Lee, L. (1999). Sociability, school experience, and delinquency. Youth \& Society, 31(2), 199-223.

McKnight, L. R. \& Loper, A. B. (2002). The effect of risk and resilience factors on the prediction of delinquency in adolescent girls. School Psychology International, 23(2), 186-198.

Miller, D., Trapani, C., Fejes-Mendoza, K. \& Eggleston, C. (1995). Adolescent female offenders: Unique considerations. Journal of Adolescence, 30, 429-435.

Nurse, A. N. (2002). The structure of the juvenile prison. Youth \& Society, 32(3), 360-394.

Polanczyk, G. V., Zavaschi, M. L., Benetti, S., Zenker, R. \& Gammerman, P. W. (2003). Violência sexual e sua prevalência em adolescentes de Porto Alegre, Brasil. Revista de Saúde Pública, 37(1), 8-14.

Regnerus, M. D. (2002). Friend's influence on adolescent theft and minor delinquency: A developmental test of peer-reported effects. Social Science Research, 31, 681-705.

Sá, A. A. (2001). Delinqüência infanto-juvenil como uma das formas de solução da privação emocional. Psicologia: Teoria e Prática, 3(1), 13-22. 
Salzinger, S., Feldman, R. S., Stockhammer, T. \& Hood, J. (2002). An ecological framework for understanding risk for exposure to community violence and the effects of exposure on children and adolescents. Journal of Aggression and Violent Behavior, 7(5), 423-451.

Saner, H. \& Ellickson, P. (1996). Concurrent risk factor for adolescent violence. Journal of Adolescent Health, 19(2), 94-103.

Sheley, J. F., Mc Gee, Z. T. \& Wright, J. D. (1992). Gun-related violence in and around inner-city schools. American Journal of Diseases of Children, 146, 677-682.

Siegel, J. A. \& Williams, L. M. (2003). The relationship between child sexual abuse and female delinquency and crime: A prospective study. Journal of Research in Crime and Delinquency, 40(1), 71-94.

Silva, D. F. M. \& Hutz, C. S. (2002). Abuso infantil e comportamento delinqüente na adolescência: Prevenção e intervenção. Em C. S. Hutz (Org.), Situações de risco e vulnerabilidade na infância e na adolescência: Aspectos teóricos e estratégias de intervenção (pp. 153-185). São Paulo: Casa do Psicólogo.

Silva, D. F. M. (2002). O desenvolvimento das trajetórias do comportamento delinqüente em adolescentes autores de atos infracionais. Tese de Doutorado. Programa de Pós-Graduação em Psicologia do Desenvolvimento, UFRGS, Porto Alegre.

Steinberg, L. (1999). Adolescence. New York: Knopf.

Storvoll, E. E. \& Wichstrom, L. (2002). Do the risk factors associated with conduct problems in adolescents vary according to gender? Journal of Adolescence, 25(2), 183-202.

Storvoll, E. E. \& Wichstrom, L. (2003). Gender differences in changes in and stability of conduct problems from early adolescence to early adulthood. Journal of Adolescence, 26, 413429.
Agradecimento às alunas do Curso de Psicologia da UNISINOS Jeane Lessinger Borges e Samara Silva dos Santos, pela colaboração na coleta e tabulação dos dados, e à FAPERGS e CNPq. 